\title{
Distinct Frontoparietal Networks Set the Stage for Later Perceptual Identification Priming and Episodic Recognition Memory
}

\author{
Maria Wimber, Hans-Jochen Heinze, and Alan Richardson-Klavehn \\ Department of Neurology, University of Magdeburg, 39120 Magdeburg, Germany
}

Recent imaging evidence suggests that a network of brain regions including the medial temporal lobe, ventrolateral prefrontal cortex, and dorsal posterior parietal cortex supports the successful encoding of long-term memories. Other areas, like the ventral posterior parietal and dorsolateral prefrontal cortices, have been associated with encoding failure rather than success. In line with the transfer-appropriate processing view, we hypothesized that distinct neural networks predict successful encoding depending on whether the later memory test draws primarily on perceptual or conceptual memory representations. Following an encoding phase, memory was assessed in a combined incidental perceptual identification and intentional recognition memory test. We found that during encoding, activation in ventral posterior parietal and dorsolateral prefrontal cortex predicted successful perceptual identification priming, whereas activation in ventrolateral prefrontal and dorsal posterior parietal cortex predicted successful recognition memory. Extending recent theories of attention to memory, the results suggest that ventral parietal regions support stimulus-driven attention to perceptual item features, forming memories accessed by later perceptual memory tests, whereas dorsal parietal regions support attention to meaningful item features, forming memories accessed by later conceptual memory tests.

\section{Introduction}

Functional neuroimaging research has now uncovered a network of brain regions that appears crucial for the successful formation of new long-term memories (Blumenfeld and Ranganath, 2007; Uncapher and Wagner, 2009), which includes the medial temporal lobes, left ventrolateral prefrontal cortex (PFC), and dorsal posterior parietal cortex (PPC). These areas typically show so called "difference due to later memory" (DM) effects (Paller et al., 1987), that is, increased activation at encoding is associated with an increased likelihood that information will be later remembered. Other brain areas show reverse DM effects, with increased activation at encoding being associated with a decreased likelihood that information will be later remembered (Otten and Rugg, 2001a; Daselaar et al., 2004; Shrager et al., 2008).

Similar DM effects have been reported under a number of different encoding conditions (Otten and Rugg, 2001b; Otten et al., 2001), but little attention has been paid to the role of the later memory test, with most studies using recognition memory tests (Otten and Rugg, 2001a,b; Otten et al., 2001, 2002). Cognitive theory, in contrast, has long appreciated the strong interactions between encoding and retrieval processes. According to transferappropriate processing theory (Morris et al., 1977), memory performance depends on the degree of overlap between cognitive

Received Feb. 3, 2010; revised June 14, 2010; accepted July 27, 2010.

This research was funded by a project grant from the German Research Foundation (Deutsche Forschungsgemeinschaft, Grant RI1847/1-1) to A.R.-K. and H.-J.H. We thank Iris Müller and Denise Göttert for assistance with data acquisition, and Simon HansImayr and two anonymous reviewers for their very helpful comments.

Correspondence should be addressed to Dr. Maria Wimber, Department of Neurology, Leipziger Straße 44, Zenit I/Room 284, 39120 Magdeburg, Germany. E-mail: maria.wimber@med.ovgu.de.

DOI:10.1523/JNEUROSCI.0588-10.2010

Copyright $\odot 2010$ the authors $\quad$ 0270-6474/10/3013272-09\$15.00/0 operations at encoding and at retrieval. Recognition tests are intentional memory tests that typically benefit from attending to conceptual aspects of items at encoding; by contrast, tests of perceptual identification priming are incidental memory tests that typically benefit from attending to perceptual features of items at encoding (Jacoby, 1983; Richardson-Klavehn et al., 1994b) [for review, see Roediger and McDermott (1993) and RichardsonKlavehn et al. (2009)]. Thus, there is no good or bad encoding, because successful memory formation depends on whether the aspects of an item attended to at encoding are relevant for the later test. Brain areas showing reverse DM effects for later intentional-conceptual memory might, therefore, actually show positive DM effects for later incidental-perceptual memory.

Recent neurocognitive theorizing has focused on the role of attentional processes supported by posterior parietal cortex for long-term memory encoding and retrieval (Cabeza, 2008; Cabeza et al., 2008; Ciaramelli et al., 2008). Interestingly, the majority of positive DM effects have included dorsal posterior parietal areas that support controlled, goal-directed attention (Corbetta and Shulman, 2002; Cabeza, 2008; Uncapher and Wagner, 2009). By contrast, negative DM effects have exclusively been found in ventral parietal areas that have been associated with perceptually driven attentional capture (Corbetta and Shulman, 2002; Uncapher and Wagner, 2009), raising the interesting hypothesis that these brain areas might show positive DM effects if the later test draws primarily on perceptual rather than conceptual memory representations. We tested this hypothesis in the current experiment. Participants underwent fMRI scanning while encoding verbal material, followed by a two-stage testing procedure that assessed both incidental perceptual identification priming and intentional recognition memory. 


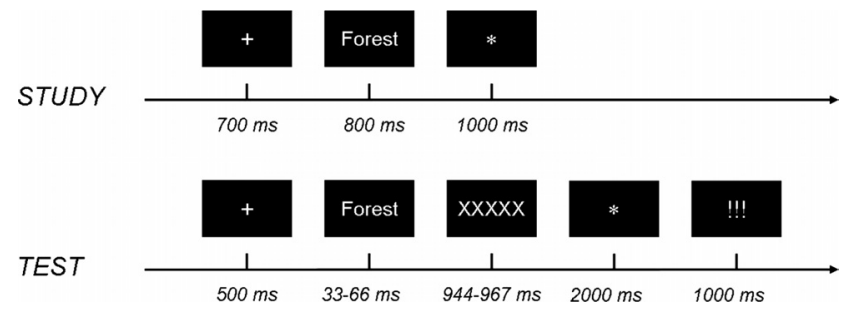

Figure 1. Experimental procedure, with stimulus durations. Participants encoded words in a syllable judgment task. A perceptual identification/recognition memory test followed, during which they had to identify briefly presented, masked words, and to judge identified words as studied or nonstudied. Based on test performance, words presented at encoding were classified as later identified and judged as studied (remembered: $R$ ), later identified and judged as nonstudied (primed: P), or later nonidentified (nonID).

\section{Materials and Methods}

Participants. Twenty-three right-handed, healthy volunteers (10 male; mean age, 25.0 years; age range, $20-35$ years) were paid to participate in the experiment after giving their written informed consent. The experiment was conducted in accordance with the guidelines of the ethics committee of the University of Magdeburg Medical Faculty. Three participants were excluded from data analysis, one because of a technical problem with response recording, and two because of too few correct word identifications. An additional nine healthy volunteers participated in a further purely behavioral experiment (see below for details).

Materials. Materials were 540 German words drawn from a larger pool that has been successfully used in prior memory studies (Schott et al., 2005, 2006). These 540 words were separated into three lists with 180 words each, matched for mean word frequency (according to the CELEX database) and word length. Assignment of list to scanning session was counterbalanced across participants, as was assignment of the words as studied or nonstudied.

Behavioral procedure. The experiment consisted of three scanning sessions, each comprising one full study-test cycle, with a short break between sessions (Fig. 1). In the study phase, 120 words were encoded in a syllable counting task. Study trials consisted of a fixation cross presented for $700 \mathrm{~ms}$, followed by a word for $800 \mathrm{~ms}$, followed by an asterisk for $1000 \mathrm{~ms}$, the latter cuing participants to indicate via button press whether the word contained exactly two or any other number of syllables. Every 10 th study trial was followed by a 16 s fixation period. Participants were instructed to perform the syllable counting as accurately as possible, and not to memorize the items. However, they were informed about the upcoming test phase before entering the scanner, so it cannot be ruled out that some participants tried to memorize the study items.

During the subsequent perceptual identification/recognition memory test, the 120 studied words were randomly intermixed with 60 new, nonstudied, words. Test trials started with $500 \mathrm{~ms}$ of fixation, followed by a word that was briefly flashed for 33-66 ms (adapted for individual thresholds in a training session; see below), followed by a mask ("XXXXX") for 944-967 ms, an asterisk for $2000 \mathrm{~ms}$, and three exclamation marks for $1000 \mathrm{~ms}$. Participants were asked to concentrate on identifying the word, and upon presentation of the asterisk, to indicate via a button press whether they could identify the word and thought it was on the prior list (index finger), could identify the word but thought that it was new (middle finger), or were not able to identify the word at all (ring finger). The three exclamation marks prompted participants to say out loud the word they had identified, or respond with "weiter" (German for "pass") in case they had not been able to identify the word. As in the study phase, a 16 s fixation period followed every 10th trial. Based on participants' test performance, study trials were sorted post hoc into laterremembered items ( $\mathrm{R}$; words that were later identified and correctly recognized as studied), later-primed items ( $\mathrm{P}$; words that were later identified but not recognized as studied), and later-nonidentified items (nonID; words that later elicited no identification response, or were incorrectly identified as other words). This classification allowed us to isolate neural processes at encoding specific for later recognition memory by comparing later-remembered with later-primed words, and neu- ral processes at encoding specific for later perceptual identification priming, uncontaminated by neural processes at encoding specific for later recognition memory, by comparing later-primed and laternonidentified words (see Schott et al., 2005, 2006; Voss and Paller, 2008). With this procedure, studied/nonstudied judgments, resulting in classification into the $\mathrm{R}$ and $\mathrm{P}$ item categories, could only be made on items that were successfully identified. Thus, there was no category of "forgotten" items comparable to prior studies on recognition DM effects. Instead, there were studied items later forgotten due to recognition memory failure, but nonetheless successfully identified ( $\mathrm{P}$ items), and studied items later "forgotten" due to unsuccessful identification (nonID items). We were unable to determine which of the nonID items would have been remembered and forgotten had these items been presented in a standard recognition test.

Preexperimental training. Before entering the scanner, participants completed up to three short practice sessions to make them familiar with the general procedure, and to determine their individual perceptual thresholds. A practice session was a short version of a study-test cycle with only 12 study words and 18 test words (12 studied, 6 nonstudied), using the same timing parameters as later during scanning. During the first practice session, words in the perceptual identification test were masked after $66 \mathrm{~ms}$. If a participant was able to identify $>50 \%$ of the nonstudied words, presentation duration was lowered to $50 \mathrm{~ms}$ in a second practice session and, if the participant still identified $>50 \%$ of the nonstudied items in that session, further lowered to $33 \mathrm{~ms}$ in a third practice session. Thus, one, two, or three practice sessions were conducted, depending on the presentation duration at which performance on nonstudied words dropped to $<50 \%$. Presentation duration determined this way was used in the first scanning session, with the possibility to adjust them up or down in case a participant performed at floor or ceiling during scanning (which was the case in only two participants, with presentation duration lowered from 66 to $50 \mathrm{~ms}$ after the first run in one case, and raised from 33 to $50 \mathrm{~ms}$ in the other case).

Behavioral experiment. To clarify the basis of recognition memory (studied vs nonstudied) judgments during the fMRI experiment, nine additional healthy participants (six female, mean age 22.1 years, range 20-27 years) were paid to participate in a purely behavioral experiment using the same perceptual identification/recognition memory test as in the fMRI experiment. Participants completed three runs with 180 words (120 targets, 60 distracters) each. The runs differed in the recognition memory judgment required after perceptual identification, resulting in three within-participants test conditions (OLD/NEW vs R/K/G vs CONF). Order of test condition was counterbalanced using a balanced Latin square, with each test condition being undertaken first, second, and third equally often across participants (three participants per order of tests). The procedure in all three test conditions closely paralleled the one used in the fMRI experiment. Preexperimental training and determination of presentation duration took place before the three study-test runs, and resembled that for the fMRI experiment, except that participants always received three practice sessions, one with each of the three kinds of test instructions. Study phases did not differ from those in the fMRI experiment, with the exception that there were no resting baseline periods in the behavioral experiment. Test trials always started with $500 \mathrm{~ms}$ of fixation, followed by an item presented for 33-66 ms, directly followed by a mask for 1944-1977 ms. Participants were asked to give a verbal response while the mask was still on the screen, and to name the word if they were able to identify it, or to respond with "weiter" (German for "pass") if they were not able to identify the item.

The three test conditions differed only in the type of memory judgment participants had to give after the oral response. In the OLD/NEW condition, as in the fMRI experiment, the mask was followed by the digits 1 and 2 presented for $2000 \mathrm{~ms}$, cuing participants to press the " 1 " button on the numeric pad of the keyboard if they thought that the item that they had just identified was studied, and the " 2 " button if they thought that the item was nonstudied. In the R/K/G condition, a studied/nonstudied judgment was given first ( 1 = studied, 2 = nonstudied), but each "studied" response was then followed by the digits 1 to 3 for another $1500 \mathrm{~ms}$, and participants indicated via button press whether their "studied" judgment was based on conscious recollection of the contextual details of the 
study episode ("1," Recollect), a strong feeling of familiarity with the word within the experimental context ("2," Know), or simple guessing ("3," Guess). Recollect, Know, and Guess judgments were made following the studied/nonstudied judgment (i.e., only for words judged studied) because of a risk that participants treat these responses similarly to confidence ratings when asked to simultaneously make Recollect, Know, Guess, and Nonstudied judgments. The judgments are, by contrast, supposed to index qualitatively different states of memory awareness during recognition memory, and they provide different information about the subjective basis of recognition than do confidence judgments. For a detailed description and discussion of these test instructions, and relevant data, see Gardiner and Richardson-Klavehn (2000). Note that Recollect judgments are normally termed Remember judgments (Gardiner and Richardson-Klavehn, 2000), but that we adapt the terminology here to avoid confusion with the later-remembered $(\mathrm{R})$ category of items that we use for interpretation of the fMRI data. In the CONF condition, the mask was directly followed by a screen showing the digits 1 to 6 (presented for $2000 \mathrm{~ms}$ ), prompting subjects to rate their confidence that an item was studied on a scale from C1 ("very sure studied") to C6 ("very sure nonstudied"), with the responses C3 and C4 representing "tendentially studied" and "tendentially nonstudied," respectively. The additional behavioral experiment permitted us to test whether the relative percentages of $\mathrm{R}$ and $\mathrm{P}$ items observed in the fMRI experiment varied as a function of the recognition memory test instructions, and thus to assess empirically whether the P items in the fMRI experiment may have been "contaminated" by familiarity or by low-confidence recognition memory.

fMRI data acquisition and analysis. Full-brain functional images were collected on a Siemens Trio 3T scanner, using an interleaved, $\mathrm{T}^{*}$ weighted echo-planar image (EPI) sequence sensitive to blood oxygenation level-dependent (BOLD) contrast (repetition time $=2.0 \mathrm{~s}$; echo time $=35 \mathrm{~ms}$ ). Functional volumes consisted of 32 slices $(3.5 \mathrm{~mm}$ thickness) with an in-plane resolution of $3.5 \times 3.5 \mathrm{~mm}$. High resolution T1-weighted structural images were acquired from each participant before the actual experiment started. Imaging data were preprocessed and statistically analyzed using statistical parametric mapping (SPM5, Wellcome Department of Cognitive Neurology, London, UK: www.fil.ion. ucl.ac.uk/spm/). After discarding the first five images of each session, time series were corrected for differences in slice acquisition time, unwarped, and spatially realigned to the first image of the first session. Structural images were coregistered with the mean functional image, and were then normalized to a MNI (Montreal Neurological Institute, www. mni.mcgill.ca) template in standard stereotactic space using the SPM5 segmentation algorithm. Resulting normalization parameters were applied to all functional images, which were finally smoothed with an $8 \mathrm{~mm}$ FWHM Gaussian kernel.

Statistical analyses were conducted in two steps. On a single-subject level, hemodynamic responses were modeled by convolving an onset vector containing delta stick or boxcar functions at the onset of a word or fixation period, respectively, with a first-order canonical hemodynamic response function (Friston et al., 1994). Resulting time series were then used as regressors in a voxelwise, fixed effects general linear model, treating slow signal components $(<256 \mathrm{~s})$ as confounds. Study phase data were modeled by three event-related covariates for $\mathrm{R}, \mathrm{P}$, and nonID items, a covariate capturing motor responses, and a blocked covariate for the $16 \mathrm{~s}$ fixation periods. Session-specific effects and movement parameters determined during realignment were included in the model. For the above mentioned planned comparisons, participants' statistical parametric maps of intentional-conceptual $(\mathrm{R}>\mathrm{P})$ and incidental-perceptual $(\mathrm{P}>$ nonID) $\mathrm{DM}$ effects were tested with one-sample $t$ tests against the null hypothesis of zero mean difference ( $p<0.001$, uncorrected for multiple comparisons, minimum 5 adjacent voxels).

\section{Results}

\section{Behavioral data}

At study, participants performed the syllable counting task at $94.2 \pm 0.8 \%(\mathrm{SEM})$ correct, and a one-way ANOVA showed that the percentage of correct responses was not significantly related
Table 1. Behavioral performance in the combined perceptual identification/ recognition test in the fMRI experiment and the behavioral experiment

\begin{tabular}{lrll}
\hline & $R$ & $P$ & NonID \\
\hline FMRI experiment & & & \\
$\quad$ Studied words & $35.2(3.6)$ & $36.7(3.6)$ & $26.9(3.3)$ \\
$\quad$ Nonstudied words & $7.7(1.6)$ & $45.5(4.1)$ & $45.0(3.8)$ \\
Behavioral experiment: 0LD/NEW condition & & & \\
$\quad$ Studied words & $37.7(6.8)$ & $33.7(4.9)$ & $26.7(4.3)$ \\
$\quad$ Nonstudied words & $11.8(2.7)$ & $43.0(6.2)$ & $41.9(4.9)$ \\
Behavioral experiment: R/K/G condition & & & \\
$\quad$ Studied words & $31.4(6.3)$ & $33.7(3.7)$ & $33.2(5.1)$ \\
$\quad$ Nonstudied words & $8.5(1.6)$ & $40.6(5.4)$ & $46.1(3.8)$ \\
Behavioral experiment: CONF condition & & & \\
$\quad$ Studied words & $40.0(6.3)$ & $32.7(2.2)$ & $24.3(4.6)$ \\
$\quad$ Nonstudied words & $10.2(2.0)$ & $48.7(4.8)$ & $37.2(3.7)$ \\
\hline
\end{tabular}

Data are mean percentages (with SEM) of items correctly identified and judged studied ( $R$ or remembered items), correctly identified and judged nonstudied (P or primed items), and nonidentified (nonID items). For studied words, the $R$ and $P$ categories correspond to recognition memory hits and misses, respectively. For nonstudied words, the $R$ and $P$ categories correspond to recognition memory false alarms and correct rejections, respectively. Data from the behavioral experiment are from a test condition replicating the fMRI experiment (OLD/NEW condition), a test condition in which participants classified items judged studied as being specifically recollected as studied (Recollect), familiar in the experimental context (Know), or guessed as studied (Guess) (R/K/G condition), and from a test condition in which participants rated their confidence that items were studied on a six-point scale ( $C 1$ = very sure studied; ( 6 = very sure nonstudied) (CONF condition). As shown here, items receiving responses C1-C3 were classified as judged studied (R items), and items receiving responses (4-C 6 were classified as judged nonstudied ( $P$ items). See supplemental Tables 3 and 4 (available at www.jneurosci.org as supplemental material) for distributions of Recollect/Know/Guess and confidence judgments.

to item type (later R: $94.6 \pm 0.8 \%$, later P: $94.0 \pm 1.2 \%$, and later nonID: $\left.94.8 \pm 0.8 \% ; F_{(2,38)}=1.04, p=0.36\right)$. Likewise, reaction times (RTs) at study were not significantly related to item type (later R: $1142 \pm 36 \mathrm{~ms}$, later P: $1144 \pm 35 \mathrm{~ms}$, and later nonID: $\left.1159 \pm 40 \mathrm{~ms} ; F_{(2,38)}=0.06, p=0.95\right)$. Thus, performance differences at study do not complicate interpretation of the fMRI data from the study phase presented here, although it should be noted that participants had to withhold their responses until 800 ms after stimulus onset, which may have biased RTs toward being similar across item types.

Performance during the combined perceptual identification/ recognition memory test in the fMRI experiment is summarized in Table 1, together with the data from the additional behavioral experiment. In the fMRI experiment, we found significant perceptual identification priming for studied compared with nonstudied words, such that participants correctly identified a higher percentage of studied words $(71.9 \pm 3.5 \%)$ than nonstudied words $\left(53.2 \pm 4.0 \% ; t_{(19)}=18.85, p<0.05\right)$. Correctly identified studied words fell into approximately equal percentages that were judged studied ( $\mathrm{R}$ items) and judged nonstudied (P items). RTs during the test phase are shown in supplemental Table 1 (available at www.jneurosci.org as supplemental material). Note that participants were asked not to press the button until $1000 \mathrm{~ms}$ after stimulus onset. A one-way ANOVA revealed that there was a significant RT difference between item types $(F(2,38)=6.17$, $p<0.05$ ), with significantly faster responses to $\mathrm{R}$ than $\mathrm{P}$ items $\left(t_{(19)}=2.72, p<0.05\right)$, to $\mathrm{R}$ than nonID items $\left(t_{(19)}=8.25, p<\right.$ $0.05)$, and to $\mathrm{P}$ than nonID items $\left(t_{(19)}=4.23, p<0.05\right)$. The RT data at test thus show that both recognition memory success and perceptual identification success were associated with faster responses.

\section{fMRI data}

DM effects for recognition memory (Fig. 2A, green; Table 2), that is, activation differences during the encoding of laterremembered compared with later-primed items $(\mathrm{R}>\mathrm{P})$, were found bilaterally in the middle temporal gyrus (BA 20/21/37), inferior and middle frontal gyri (BA 46 and 47), superior and 

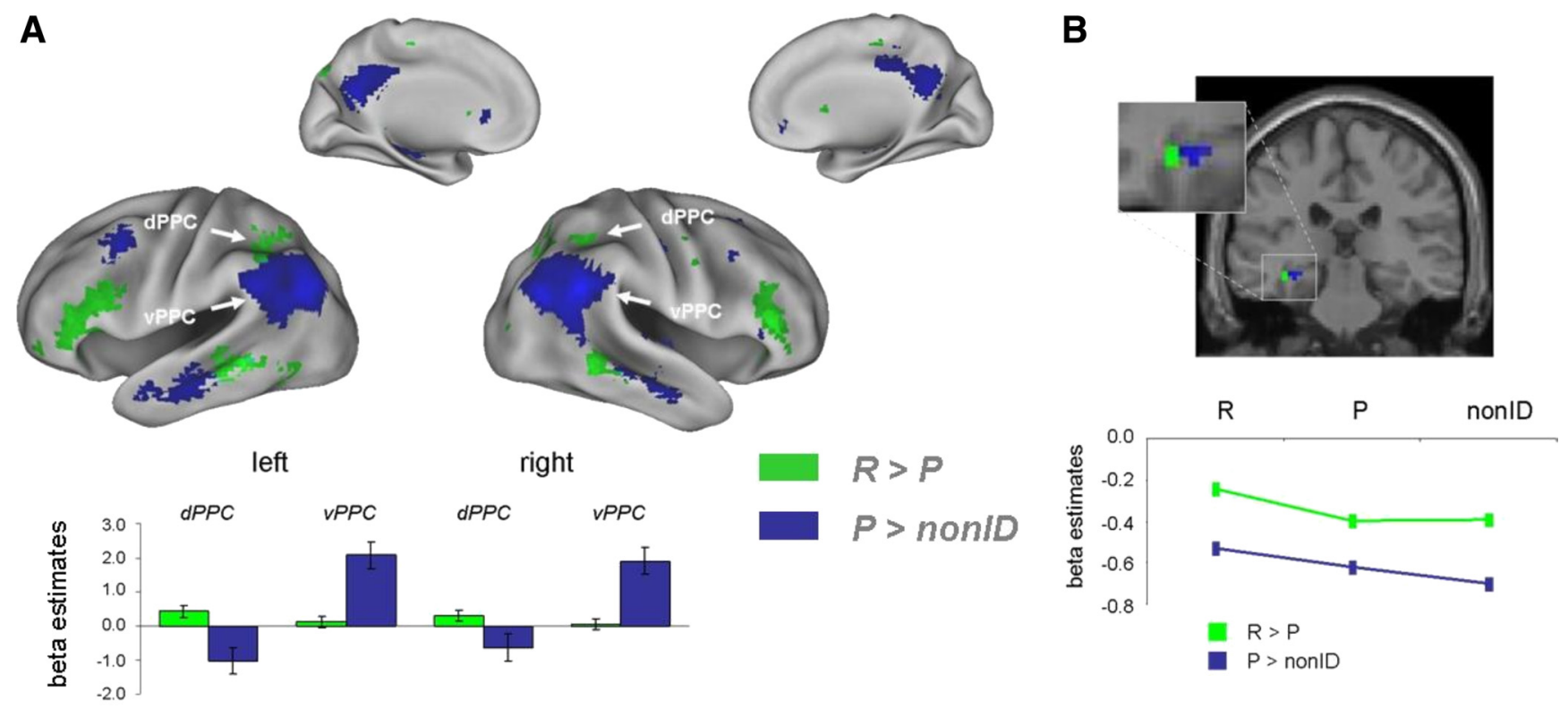

Figure 2. Encoding activations that predicted whether an item was later perceptually identified and judged studied (remembered: R), perceptually identified and judged nonstudied (primed: P), or not identified (nonID). A, Dorsal posterior parietal and ventral prefrontal regions showed DM effects for recognition memory (green), whereas ventral posterior parietal and dorsal prefrontal regions showed DM effects for perceptual identification priming (blue). Bar plots show mean eigenvalues from dorsal and ventral posterior PPC (ROIs defined from an independent half of the data, see Results). $\boldsymbol{B}$, Medial temporal clusters that predicted later recognition memory (green) and perceptual identification (blue) are depicted on a coronal section ( $y=-27$ ) of an MNI canonical T1 template in neurological orientation.

Table 2. Regions showing DM effects for recognition memory (shown in green in Fig. 2), that is, significantly more activation ( $p<0.001$ uncorrected, cluster size $\geq 5$ voxels) during the encoding of later-remembered (R) than later-primed (P) words

\begin{tabular}{|c|c|c|c|c|c|c|c|}
\hline Hemisphere & Anatomical label & $x$ & $y$ & $z$ & $B A$ & $T$ & $\overline{\text { Size }}$ \\
\hline \multirow[t]{3}{*}{ L } & Middle temporal gyrus & -51 & -42 & -12 & 20 & 7.40 & 242 \\
\hline & Middle temporal gyrus & -57 & -42 & -6 & 37 & 6.93 & \\
\hline & Middle temporal gyrus & -63 & -51 & -3 & 21 & 4.87 & \\
\hline \multirow[t]{3}{*}{$\mathrm{R}$} & Inferior frontal gyrus & 48 & 33 & 9 & 46 & 6.91 & 235 \\
\hline & Inferior frontal gyrus & 54 & 42 & 12 & 46 & 6.68 & \\
\hline & Middle frontal gyrus & 39 & 39 & -3 & 47 & 5.21 & \\
\hline \multirow[t]{3}{*}{ L } & Inferior frontal gyrus & 45 & 30 & 6 & 46 & 6.16 & 564 \\
\hline & Middle frontal gyrus & -42 & 18 & 21 & 46 & 5.87 & \\
\hline & Middle frontal gyrus & -57 & 24 & 24 & 46 & 5.64 & \\
\hline \multirow[t]{3}{*}{$\mathrm{R}$} & Middle temporal gyrus & 63 & -45 & -9 & 21 & 5.63 & 85 \\
\hline & Middle temporal gyrus & 60 & -45 & 0 & 21 & 4.89 & \\
\hline & Inferior temporal gyrus & 57 & -33 & -15 & 20 & 4.59 & \\
\hline L & Fusiform gyrus & -42 & -30 & -15 & 20 & 5.25 & 13 \\
\hline $\mathrm{L}$ & Inferior parietal lobule & -42 & -54 & 51 & 40 & 5.22 & 111 \\
\hline \multirow{3}{*}{$\mathrm{R}$} & Superior parietal lobule & 30 & -69 & 51 & 7 & 4.93 & 71 \\
\hline & Superior parietal lobule & 33 & -63 & 45 & 7 & 4.45 & \\
\hline & Middle temporal gyrus & 39 & -66 & 27 & 39 & 3.58 & \\
\hline \multirow[t]{3}{*}{$\mathrm{R}$} & Inferior parietal lobule & 39 & -45 & 39 & 40 & 4.79 & 45 \\
\hline & Superior parietal lobule & 33 & -48 & 48 & 7 & 4.33 & \\
\hline & Inferior parietal lobule & 48 & -42 & 48 & 40 & 3.84 & \\
\hline L & Precuneus & -15 & -81 & 42 & 19 & 4.54 & 21 \\
\hline \multirow[t]{2}{*}{ B } & Medial frontal gyrus & -3 & -24 & 57 & 6 & 4.49 & 18 \\
\hline & Medial frontal gyrus & 12 & -24 & 57 & 6 & 4.30 & \\
\hline L & Hippocampus & -36 & -20 & -15 & - & 4.43 & 11 \\
\hline $\mathrm{R}$ & Precentral gyrus & 45 & 0 & 30 & 6 & 4.12 & 7 \\
\hline L & Superior parietal lobule & -27 & -42 & 48 & 40 & 3.92 & 5 \\
\hline $\mathrm{R}$ & Fusiform gyrus & 45 & -51 & -15 & 37 & 3.84 & 13 \\
\hline
\end{tabular}

Rows with entries for hemisphere and size refer to peak activations in a cluster. L, Left hemisphere; $R$, right hemisphere; B, bilateral; BA, approximate Brodmann area labeled according to the Talairach Daemon; size, cluster size in voxels ( $3 \times 3 \times 3$ mm).

inferior parietal lobule (BA 7 and BA 40, respectively), medial and lateral premotor areas (BA 6), hippocampus, and fusiform gyrus (BA 20/37). The major DM effects for perceptual identification priming ( $\mathrm{P}>$ nonID) (Fig. $2 A$, blue; Table 3) were located bilaterally in more ventral (BA 39 and 40) and medial
(BA 31) portions of the parietal lobe, including supramarginal and angular gyrus, as well as posterior areas around the temporoparietal junction, in posterior and dorsal aspects of the middle and superior frontal gyri (BA 6/8/9/10), and in bilateral middle and inferior temporal gyri (BA 20/21). 
Table 3. Regions showing DM effects for perceptual identification priming (shown in blue in Fig. 2), that is, significantly more activation ( $p<0.001$ uncorrected, cluster size $\geq 5$ voxels) during the encoding of $P$ than nonID items

\begin{tabular}{|c|c|c|c|c|c|c|c|}
\hline Hemisphere & Anatomical label & $x$ & $y$ & $Z$ & $\mathrm{BA}$ & $T$ & Size \\
\hline \multirow[t]{3}{*}{ B } & Precuneus & -12 & -60 & 21 & 31 & 9.89 & 662 \\
\hline & Precuneus & 12 & -57 & 24 & 31 & 6.09 & \\
\hline & Precuneus & 9 & -54 & 33 & 31 & 5.45 & \\
\hline \multirow[t]{3}{*}{ R } & Inferior parietal lobule & 57 & -48 & 36 & 40 & 9.46 & 520 \\
\hline & Middle temporal gyrus & 45 & -66 & 27 & 39 & 8.79 & \\
\hline & Middle temporal gyrus & 51 & -60 & 24 & 39 & 7.16 & \\
\hline \multirow[t]{3}{*}{$\mathrm{L}$} & Superior occipital gyrus & -42 & -78 & 36 & 19 & 8.34 & 520 \\
\hline & Superior temporal gyrus & -54 & -63 & 27 & 39 & 8.06 & \\
\hline & Middle temporal gyrus & -54 & -69 & 30 & 39 & 7.42 & \\
\hline \multirow[t]{2}{*}{$\mathrm{L}$} & Parahippocampal gyrus & -33 & -36 & -9 & 37 & 6.57 & 55 \\
\hline & Hippocampus & -30 & -21 & -15 & - & 5.40 & \\
\hline L & Middle frontal gyrus & -42 & 12 & 45 & 6 & 6.31 & 94 \\
\hline \multirow[t]{3}{*}{$\mathrm{R}$} & Inferior temporal gyrus & 60 & -18 & -15 & 20 & 5.89 & 150 \\
\hline & Inferior temporal gyrus & 63 & -12 & -21 & 20 & 5.33 & \\
\hline & Middle temporal gyrus & 69 & -33 & -6 & 21 & 4.88 & \\
\hline \multirow[t]{3}{*}{$\mathrm{L}$} & Inferior temporal gyrus & -60 & -18 & -15 & 20 & 5.86 & 170 \\
\hline & Fusiform gyrus & -60 & -12 & -27 & 20 & 4.78 & \\
\hline & Middle temporal gyrus & -54 & 3 & -21 & 21 & 4.74 & \\
\hline $\mathrm{R}$ & Posterior cingulate & 21 & -54 & 18 & 30 & 5.55 & 52 \\
\hline \multirow[t]{2}{*}{$\mathrm{R}$} & Insula & 45 & -15 & 3 & 13 & 5.00 & 61 \\
\hline & Precentral gyrus & 54 & -6 & 6 & 6 & 4.51 & \\
\hline R & Middle frontal gyrus & 24 & 21 & 48 & 8 & 4.65 & 41 \\
\hline L & Superior temporal gyrus & -45 & -18 & 3 & 22 & 4.60 & 12 \\
\hline $\mathrm{R}$ & Anterior cingulate & 3 & 30 & 0 & 32 & 4.53 & 12 \\
\hline \multirow[t]{2}{*}{$\mathrm{R}$} & Postcentral gyrus & 39 & -18 & 45 & 4 & 4.49 & 21 \\
\hline & Superior frontal gyrus & 33 & 30 & 57 & 8 & 4.05 & \\
\hline \multirow[t]{2}{*}{$\mathrm{R}$} & Transverse temporal gyrus & 48 & -27 & 12 & 41 & 4.40 & 30 \\
\hline & Superior temporal gyrus & 63 & -21 & 9 & 42 & 4.37 & \\
\hline $\mathrm{R}$ & Anterior cingulate & 9 & 42 & -6 & 32 & 4.00 & 6 \\
\hline \multirow[t]{2}{*}{$\mathrm{R}$} & Middle frontal gyrus & 48 & 18 & 42 & 8 & 4.00 & 11 \\
\hline & Precentral gyrus & 36 & 15 & 36 & 9 & 3.71 & \\
\hline $\mathrm{L}$ & Superior frontal gyrus & -21 & 54 & 9 & 10 & 3.95 & 9 \\
\hline $\mathrm{R}$ & Hippocampus & 27 & -18 & -18 & - & 3.90 & 8 \\
\hline
\end{tabular}

Rows with entries for hemisphere and size refer to peak activations in a cluster. L, Left hemisphere; $\mathrm{R}$, right hemisphere; B, bilateral; BA, approximate Brodmann area labeled according to the Talairach Daemon; size, luster size in voxels ( $3 \times 3 \times 3 \mathrm{~mm}$ ).

In the light of recent claims of a role for the posterior parietal lobe in memory encoding (see Introduction and Discussion), we were particularly interested in the functional dissociation between ventral and dorsal posterior parietal lobe that was apparent in the present data. To underpin the claim of a true double dissociation, we ran an additional split-half analysis to be able to define regions of interest (ROIs) on one half of the data from each participant, and to then test for an interaction on the second, unbiased half. The onset vectors of the three item types at encoding were randomly split into two halves (with the restriction that the same number of onsets were picked from each quarter of the original vector), and new first-level (single-subject) models were estimated, now containing six instead of the original three covariates of interest (R1, R2, P1, P2, nonID1, nonID2). Contrasts performed on one half of the items yielded significant differences between remembered and primed items $(\mathrm{R} 1>\mathrm{P} 1)$ in bilateral dorsal posterior parietal cortices, and between primed and nonidentified items ( $\mathrm{P} 1>$ nonID1) in bilateral ventral posterior parietal cortices (see supplemental Table 2, available at www. jneurosci.org as supplemental material).

The four regions derived from these contrasts were used as ROIs, extracting mean activation estimates (eigenvalues) from the two DM contrasts (R2 > P2, and P2 > nonID2) using EasyROI (http://www.sbirc.ed.ac.uk/cyril/). Those estimates were then entered into a 2-by-2 ANOVA with the factors REGION and CONTRAST, with left and right hemisphere analyzed separately (Fig. $2 \mathrm{~A}$, bar plots). This analysis revealed a significant
REGION $\times$ CONTRAST interaction in both hemispheres (left: $F_{(2,38)}=44.91, p<0.05$; right: $\left.F_{(2,38)}=36.90, p<0.05\right)$. Post hoc $t$ tests showed that in bilateral dorsal PPC, the difference between later $\mathrm{R}$ and $\mathrm{P}$ items was significantly larger than the difference between $\mathrm{P}$ and nonID items (left: $t_{(19)}=2.70, p<0.05$; right: $\left.t_{(19)}=1.86, p<0.05\right)$, whereas in bilateral ventral PPC, the difference between $\mathrm{P}$ and nonID items was significantly larger than the difference between $\mathrm{R}$ and $\mathrm{P}$ items (left: $t_{(19)}=4.81, p<$ 0.05; right: $\left.t_{(19)}=4.45, p<0.05\right)$.

Interestingly, the hippocampal complex, including the hippocampus proper and parahippocampal cortex, showed both kinds of DM effects (Fig. 2B; Tables 2, 3). Post hoc, descriptive ROI analyses, extracting activation estimates (eigenvalues) for all three item types ( $\mathrm{R}, \mathrm{P}$, and nonID) compared with the fixation baseline, revealed that the two neighboring MTL regions showed different patterns, with one cluster (peak located at $-36-20$ -15 , hippocampus) showing an increase (or rather a reduced decrease) that was specific for $\mathrm{R}$ items (Fig. $2 \mathrm{~B}$, green line), and the other one (peak located at $-33-36-9$, comprising parts of parahippocampal BA 37 and the hippocampus) showing a linear activation decrease from $\mathrm{R}$ to $\mathrm{P}$ to nonID items (Fig. $2 \mathrm{~B}$, blue line).

In examining DM effects for later recognition memory, the contrast $\mathrm{P}>\mathrm{R}$ did not yield significant activations, which may appear surprising in view of the reverse recognition DM effects reported in previous research. However, it is, first, important to note that the $\mathrm{P}>\mathrm{R}$ comparison in the current study is not equiv- 
alent to the reverse recognition DM effect (nonrecognized > recognized) as calculated in previous DM studies (see Materials and Methods). Calculating the reverse recognition DM effect in the traditional way would have required our nonID items to be presented in intact form for a recognition judgment, whereas nonID items did not receive a recognition judgment. Second, the data from the $\mathrm{P}>$ nonID contrast, which show activations for later perceptual priming in areas that have previously shown reverse recognition DM effects (see Introduction and Discussion), raise the possibility that, in traditional recognition DM studies, the unrecognized item category may contain more perceptually primed items than does the recognized item category, so that the unrecognized $>$ recognized contrast may reveal activations related to later perceptual priming. Here, by contrast, we "conditionalize" on perceptual priming for both $\mathrm{R}$ and $\mathrm{P}$ items, so that the $\mathrm{P}>\mathrm{R}$ contrast might not be expected to yield significant activations. Consistent with this assertion, the $\mathrm{R}>$ nonID contrast showed activations in similar areas reported for the $\mathrm{P}>$ nonID contrast, with the activations in both of these contrasts actually consisting of reduced deactivations compared to the fixation baseline (data not shown), as is often observed in relation to the so-called default network (see Discussion).

\section{Additional behavioral data}

The finding that MTL activation predicts later perceptual priming is somewhat counterintuitive given the widely assumed selective role of the hippocampus in encoding for later conscious episodic recollection (e.g., Schott et al., 2006). One valid concern with respect to these data, as well as the other activations predicting later perceptual priming, is that the $\mathrm{P}$ (primed) item category might have been subject to contamination by familiarity or by low-confidence recognition memory, which might have happened if participants answered "studied" only if they specifically recollected the study episode, or answered "studied" only if they were very sure that an item was studied. Indeed, according to a signal-detection analysis (e.g., Yonelinas, 1999), within correctly identified items, participants in the fMRI experiment were somewhat more conservative than neutral in responding "studied," because their criterion measure of 0.67 [criterion $=-0.5\left(z_{\text {hit rate }}+\right.$ $\left.z_{\text {false alarm rate }}\right)$ ] was larger than zero, with zero corresponding to a completely neutral response criterion.

The additional behavioral experiment provided important information in this regard (see Table 1). In the replication of the fMRI procedure (OLD/NEW condition), performance was similar to performance in the fMRI sample, with a similar criterion from a signal-detection analysis (0.60). In the $\mathrm{R} / \mathrm{K} / \mathrm{G}$ condition, when participants made a "studied" response, they were permitted to classify the items as being specifically episodically recollected as studied (Recollect), strongly familiar in the experimental context (Know), or simply guessed as studied (Guess) (see Gardiner and Richardson-Klavehn, 2000). If familiar items or items that could be guessed as studied were contained in the P category (i.e., items judged nonstudied) in the fMRI experiment and the OLD/ NEW condition, the R/K/G test instructions should shift such items into the $\mathrm{R}$ category, resulting in lower percentage of $\mathrm{P}$ items in the $\mathrm{R} / \mathrm{K} / \mathrm{G}$ condition compared with the fMRI experiment and the OLD/NEW condition. As shown in Table 1, however, the estimated percentage of $\mathrm{P}$ items did not substantially change, suggesting that the vast majority of the $\mathrm{P}$ items in the fMRI experiment and the OLD/NEW condition were truly nonrecognized (see also Richardson-Klavehn et al., 1994a, for convergent evidence). Furthermore (supplemental Table 3, available at www. jneurosci.org as supplemental material), a relatively low percent- age of the "studied" responses to studied words in the $\mathrm{R} / \mathrm{K} / \mathrm{G}$ condition were based on specific episodic recollection, and a relatively high percentage were based on familiarity, as would be expected given the "shallow" syllable counting task used at study (see Gardiner and Richardson-Klavehn, 2000). There were also some items simply guessed as studied, with the Guess responses not discriminating between studied and nonstudied items, as is typically found (see Gardiner and Richardson-Klavehn, 2000). These results further encourage the conclusion that the $\mathrm{P}$ item category in the fMRI experiment and the OLD/NEW condition was substantially composed of items truly nonrecognized as studied.

Adopting a signal-detection approach (Yonelinas, 1999), as represented by the CONF (confidence judgment) condition in the behavioral experiment, provided further evidence for this conclusion (supplemental Table 4, available at www.jneurosci. org as supplemental material). Classifying items judged as very sure studied, sure studied, and tendentially studied (C1-C3) as R items, and items judged tendentially nonstudied, sure nonstudied, and very sure nonstudied (C4-C6) as P items, corresponding to a neutral response criterion, resulted in reasonably accurate estimates of the percentages of these items in the fMRI experiment and the OLD/NEW condition (Table 1).

Moreover, classifying items eliciting familiarity (Know responses in the $\mathrm{R} / \mathrm{K} / \mathrm{G}$ condition) or low-confidence "studied" judgments (C3 responses in the CONF condition) as $\mathrm{P}$ items, rather than $\mathrm{R}$ items, resulted in statistically significant overestimates of the percentage of $\mathrm{P}$ items in the OLD/NEW condition, and by implication, in the fMRI experiment (see supplemental Results). In sum, the results suggest that very few of the P items were "contaminated" with familiarity or low-confidence recognition memory. Perceptual fluency, as assessed by perceptual identification priming, is frequently asserted to contribute to feelings of familiarity or to low-confidence recognition memory (for discussion, see Conroy et al., 2005). However, the data from the current $\mathrm{P}$ items are more consistent with other findings suggesting that perceptual priming can occur without any awareness at all of a prior study episode [e.g., Richardson-Klavehn et al. (1994a), Paller et al. (2003), Conroy et al. (2005), and Schott et al. $(2005,2006)]$.

\section{Discussion}

Two distinct frontoparietal cortical networks predicted later incidental perceptual identification priming and later intentional recognition memory (Fig. $2 \mathrm{~A}$ ). Activation in dorsal posterior parietal regions predicted later recognition memory, replicating prior studies (Uncapher and Wagner, 2009), whereas activation in ventral posterior parietal cortex predicted later perceptual identification priming. Moreover, activity in prefrontal areas was also differentially related to later memory, with ventrolateral areas showing the typical positive recognition DM effect, and dorsolateral and medial frontal areas showing positive DM effects for perceptual priming.

Positive DM effects in the posterior parietal lobe are typically found in the dorsal portion, comprising the intraparietal sulcus and adjacent superior parietal lobule (Uncapher and Wagner, 2009). In line with a dual-attention view (Corbetta and Shulman, 2002; Cabeza, 2008; Cabeza et al., 2008; Ciaramelli et al., 2008), dorsal activations have been taken as reflecting goal-directed attention that supports the formation of episodic memories, as assessed in intentional recognition tests, because it focuses attentional resources on processing the conceptual aspects of an item (Cabeza et al., 2008; Uncapher and Wagner, 2009). The present 
results confirm this assumption, in that the parietal correlates of encoding for later recognition memory were located around the intraparietal sulcus, which is part of the dorsal attentional system (Corbetta and Shulman, 2002).

However, we expand these prior findings by demonstrating that activity of the ventral parietal cortex, in the vicinity of the supramarginal gyrus, is strongly predictive of later perceptual identification priming. This finding is remarkable, given that exactly the same region has revealed negative DM effects, that is, relatively more activation for later forgotten than remembered items (Otten and Rugg, 2001a; Daselaar et al., 2004; Shrager et al., 2008; Uncapher and Wagner, 2009). The finding that activity in this region predicts successful later identification priming therefore helps to elucidate the encoding processes supported by ventral posterior parietal cortex. It has been speculated, again based on the dual-attention view (Corbetta and Shulman, 2002), that ventral parietal activation reflects attentional capture by salient, superficial item features (Uncapher and Wagner, 2009). We provide direct empirical evidence for this idea, suggesting that ventral parietal activation reflects a shift of selective attention from goal-directed conceptual to stimulus-driven perceptual processing (e.g., focusing attention on visual attributes of an item). Such orienting of selective attention is known to be beneficial for later incidental perceptual priming, but detrimental for intentional recognition memory (Jacoby, 1983; Richardson-Klavehn et al., 1994b), although in some cases, encoding perceptual stimulus features might also facilitate later recognition memory [e.g., when items are perceptually distinct (see Uncapher and Wagner, 2009)].

Prefrontal correlates of successful memory formation are typically located on inferior, and sometimes middle, frontal gyri (Blumenfeld and Ranganath, 2007; Spaniol et al., 2009). Our results confirm that activation in ventrolateral prefrontal areas is primarily associated with later intentional recognition memory, as revealed by the contrast of later-remembered versus primed items. On the other hand, later perceptual identification priming, but not recognition memory, was predicted by superior frontal activation, in an area that has also been associated with reverse DM effects (Otten and Rugg, 2001a; Clark and Wagner, 2003; Daselaar et al., 2004). Some authors have argued that this region supports the organization of the to-be-encoded material into "chunks" that are more easily remembered, provided that the later test emphasizes relations between successive items, or between item and context (Staresina and Davachi, 2006; Summerfield et al., 2006; Blumenfeld and Ranganath, 2007). Our findings suggest that dorsolateral prefrontal cortex may also support much lower-level encoding processes that set the stage for later perceptual priming. Attentional binding is one such prerequisite for priming (Hayman and Jacoby, 1989; Schacter et al., 1991; Richardson-Klavehn and Gardiner, 1998), and could be achieved via the strong connections of this area with the ventral posterior parietal lobe (Petrides and Pandya, 1999; Petrides, 2005; Umarova et al., 2010). Support for a binding function of the superior PFC comes from an fMRI investigation showing that connectivity between this same area and modality-specific late visual areas predicts successful associative recognition (Summerfield et al., 2006).

Three further aspects of the present data deserve mention. First, a recent meta-analysis concluded that lateral parietal DM effects are independent of the test used to assess memory (Uncapher and Wagner, 2009), and differential DM effects due to different testing procedures have indeed been localized mainly to prefrontal and medial temporal regions (Ranganath et al., 2004; Staresina and Davachi, 2006; Summerfield et al., 2006). However, all these studies used different intentional memory tests, which might not be sensitive to differential parietal contributions, because performance in these tests generally benefits from conceptual processing at encoding. We are aware of only one prior study that reported distinct encoding correlates of later priming and recognition memory (Schott et al., 2006), which used a word stem completion task and found a parietal pattern suggestive of the very distinctive pattern we found in the present experiment.

Second, our study design comprised a passive fixation baseline for assessing encoding-related increases and decreases. Our data suggest that the neural correlates of successful encoding for later recognition memory were primarily driven by task related increases, whereas the neural correlates of encoding for later perceptual identification priming were primarily driven by taskrelated decreases. The network of brain regions predicting later perceptual identification priming (Fig. $2 \mathrm{~A}$, blue) is strikingly reminiscent of the so called default network (Shulman et al., 1997; Raichle et al., 2001) including ventrolateral and medial parietal lobe, hippocampus, and anterior cingulate. Shulman et al. (1997) suggested that this network is mainly concerned with sensory monitoring, and is suppressed during demanding cognitive tasks. Along these lines, it has been argued that default network activity reflects a stimulus-driven mode of attention (Gilbert et al., 2007; Hahn et al., 2007), which, from a memory viewpoint, would favor later perceptual identification, but not recognition memory (Jacoby, 1983; Richardson-Klavehn et al., 1994b). This argument is consistent with the finding that default network activity sometimes predicts encoding failures if memory is assessed by intentional-conceptual recall or recognition tests (Otten and Rugg, 2001a; Daselaar et al., 2004; Shrager et al., 2008).

Third, we also found hippocampal DM effects. Whereas a smaller area showed the expected pattern (Spaniol et al., 2009) of more activation during the encoding of later recognized than primed words (Fig. $2 \mathrm{~B}$, green), we were surprised to find a larger, neighboring area that was predictive of later perceptual identification priming, and showed a trend toward a recognition DM effect (Fig. 2 B, blue; Table 3). The latter finding underscores claims that information processing in the hippocampal complex might not be restricted to the episodic memory domain (Ranganath and D'Esposito, 2001; Moscovitch, 2008; Kumaran and Maguire, 2009). There have been speculations about (Ostergaard and Jernigan, 1993; Moscovitch, 2008), as well as findings of (Schott et al., 2005; Hannulah and Ranganath, 2009; Voss et al., 2009), a role of the medial temporal lobe in priming, although until now they have mainly concerned retrieval rather than encoding (but see Hannulah and Ranganath, 2009). A hippocampal role for the formation of perceptual memories is thus not inconceivable, and should be further explored.

Some incidental tests are sensitive to prior conceptual processing (Blaxton, 1989), and some intentional tests are sensitive to prior perceptual processing (Whittlesea and Williams, 2000; Holdstock et al., 2002; Voss et al., 2008). However, our claim that encoding processes leading to successful incidental perceptual identification priming are primarily perceptual, and that encoding processes leading to successful intentional recognition memory are primarily conceptual, is strongly underpinned by studies using the same memory measures. Incidental perceptual identification priming is greater following perceptual than conceptual encoding, with the same encoding conditions producing the reverse effect on intentional recognition memory (crossed double dissociations) [e.g., Jacoby (1983) and Richardson-Klavehn et al. (1994b)] [for review, see Roediger and McDermott (1993) and 
Richardson-Klavehn et al. (2009)]. Future research will show whether the neural pattern found here can be reproduced using conceptual and perceptual encoding manipulations to experimentally examine the neural correlates of transfer-appropriate processing (Morris et al., 1977).

To summarize, we combined an incidental perceptual identification test with an intentional recognition test, which allowed us to uniquely classify encoding trials as later remembered, primed, and nonidentified (Schott et al., 2005, 2006; Voss and Paller, 2008). We found that at encoding, later recognition memory was positively predicted by activation in dorsal posterior parietal and ventrolateral prefrontal areas previously associated with encoding success and with conceptually driven processing at encoding (Otten et al., 2002; Blumenfeld and Ranganath, 2007; Uncapher and Wagner, 2009). By contrast, activity in brain regions previously associated with encoding failure rather than success (Clark and Wagner, 2003; Daselaar et al., 2004; Blumenfeld and Ranganath, 2007; Shrager et al., 2008; Uncapher and Wagner, 2009) positively predicted perceptual identification priming. Our results suggest that reverse DM effects may reflect stimulus-driven attentional orienting at encoding, which is unfavorable for later recognition memory, but facilitates later perceptual identification.

\section{References}

Blaxton TA (1989) Investigating dissociations among memory measures: support for a transfer-appropriate processing framework. J Exp Psychol Learn Mem Cogn 15:657-668.

Blumenfeld RS, Ranganath C (2007) Prefrontal cortex and long-term memory encoding: an integrative review of findings from neuropsychology and neuroimaging. Neuroscientist 13:280-291.

Cabeza R (2008) Role of parietal regions in episodic memory retrieval: the dual attention processes hypothesis. Neuropsychologia 46:1813-1827.

Cabeza R, Ciaramelli E, Olson IR, Moscovitch M (2008) The parietal cortex and episodic memory: an attentional account. Nat Rev Neurosci 9:613-625.

Ciaramelli E, Grady CL, Moscovitch M (2008) Top-down and bottom-up attention to memory: a hypothesis (AtoM) on the role of the posterior parietal cortex in memory retrieval. Neuropsychologia 46:1828-1851.

Clark D, Wagner AD (2003) Assembling and encoding word representations: fMRI subsequent memory effects implicate a role for phonological control. Neuropsychologia 41:304-317.

Conroy MA, Hopkins RO, Squire LR (2005) On the contribution of perceptual fluency and priming to recognition memory. Cogn Affect Behav Neurosci 5:14-20.

Corbetta M, Shulman GL (2002) Control of goal-directed and stimulusdriven attention in the brain. Nat Rev Neurosci 3:201-215.

Daselaar SM, Prince SE, Cabeza R (2004) When less means more: deactivations during encoding that predict subsequent memory. Neuroimage 23:921-927.

Friston KJ, Holmes AP, Worsley KJ, Poline JP, Frith CD, Frackowiak RSJ (1994) Statistical parametric maps in functional imaging: a general linear approach. Hum Brain Mapp 2:189-210.

Gardiner JM, Richardson-Klavehn A (2000) Remembering and knowing. In: The Oxford handbook of memory (Tulving E, Craik FIM, eds), pp 229-244. New York: Oxford UP.

Gilbert SJ, Dumontheil I, Simons JS, Frith CD, Burgess PW (2007) Comment on "Wandering minds: the default network and stimulusindependent thought." Science 317:43.

Hahn B, Ross TJ, Stein EA (2007) Cingulate activation increases dynamically with response speed under stimulus unpredictability. Cereb Cortex 17:1664-1671.

Hannula DE, Ranganath C (2009) The eyes have it: hippocampal activity predicts expression of memory in eye movements. Neuron 63:592-599.

Hayman CA, Jacoby LL (1989) Specific word transfer as a measure of processing in the word-superiority paradigm. Mem Cognit 17:125-133.

Holdstock JS, Mayes AR, Roberts N, Cezayirli E, Isaac CL, O’Reilly RC, Norman KA (2002) Under what conditions is recognition spared relative to recall after selective hippocampal damage in humans? Hippocampus $12: 341-351$
Jacoby LL (1983) Remembering the data: analyzing interactive processes in reading. J Verb Learn Verb Behav 22:485-508.

Kumaran D, Maguire EA (2009) Novelty signals: a window into hippocampal information processing. Trends Cogn Sci 13:47-54.

Morris CD, Bransford JD, Franks JJ (1977) Levels of processing versus transfer appropriate processing. J Verb Learn Verb Behav 16:389-395.

Moscovich M (2008) The hippocampus as a "stupid", domain-specific module: implications for theories of recent and remote memory, and of imagination. Can J Exp Psychol 62:62-79.

Ostergaard AL, Jernigan TL (1993) Are word priming and explicit memory mediated by different brain structures? In: Implicit memory: New directions in cognition, development, and neuropsychology (Masson MEJ, Graf P, eds), pp 327-350. Hillsdale, NJ: Erlbaum.

Otten LJ, Rugg MD (2001a) When more means less: neural activity related to unsuccessful memory encoding. Curr Biol 11:1528-1530.

Otten LJ, Rugg MD (2001b) Task-dependency of the neural correlates of episodic encoding as measured by fMRI. Cereb Cortex 11:1150-1160.

Otten LJ, Henson RN, Rugg MD (2001) Depth of processing on neural correlates of memory encoding: relationship between findings from acrossand within-task comparisons. Brain 124:399-412.

Otten LJ, Henson RN, Rugg MD (2002) State-related and item-related neural correlates of successful memory encoding. Nat Neurosci 5:1339-1344.

Paller KA, Kutas M, Mayes AR (1987) Neural correlates of encoding in an incidental learning paradigm. Electroencephalogr Clin Neurophysiol 67:360-371.

Paller KA, Hutson CA, Miller BB, Boehm SG (2003) Neural manifestations of memory with and without awareness. Neuron 38:507-516.

Petrides M (2005) Lateral prefrontal cortex: architectonic and functional organization. Philos Trans R Soc Lond B Biol Sci 360:781-795.

Petrides M, Pandya DN (1999) Dorsolateral prefrontal cortex: comparative cytoarchitectonic analysis in the human and the macaque brain and corticocortical connection patterns. Eur J Neurosci 11:1011-1036.

Raichle ME, MacLeod AM, Snyder AZ, Powers WJ, Gusnard DA, Shulman GL (2001) A default mode of brain function. Proc Natl Acad Sci U S A 98:676-682.

Ranganath C, D’Esposito M (2001) Medial temporal lobe activity associated with active maintenance of novel information. Neuron 31:865-873.

Ranganath C, Yonelinas AP, Cohen MX, Dy CJ, Tom SM, D’Esposito M (2004) Dissociable correlates of recollection and familiarity within the medial temporal lobes. Neuropsychologia 42:2-13.

Richardson-Klavehn A, Gardiner JM (1998) Depth-of-processing effects on priming in word-stem completion: tests of the voluntary-contamination, lexical-processing, and conceptual-processing hypotheses. J Exp Psychol Learn Mem Cogn 24:593-609.

Richardson-Klavehn A, Gardiner JM, Java RI (1994a) Involuntary conscious memory and the method of opposition. Memory 2:1-29.

Richardson-Klavehn A, Lee MG, Joubran R, Bjork RA (1994b) Intention and awareness in perceptual identification priming. Mem Cognit 22:293-312.

Richardson-Klavehn A, Bergström ZM, Magno E, Markopoulos G, SweeneyReed CM, Wimber M (2009) On the intimate relationship between neurobiology and function in the theoretical analysis of human learning and memory. In: Neuroimaging of human memory: linking cognitive processes to neural systems (Rösler F, Ranganath C, Röder B, Kluwe RH, eds) pp 127-165. New York: Oxford UP.

Roediger HL, McDermott KB (1993) Implicit memory in normal human subjects. In: Handbook of neuropsychology (Boller F, Grafman J, eds), pp 63-131. Amsterdam: Elsevier.

Schacter DL, Cooper LA, Delaney SM, Peterson MA, Tharan M (1991) Implicit memory for possible and impossible objects: constraints on the construction of structural descriptions. J Exp Psychol Learn Mem Cogn 17:3-19.

Schott BH, Henson RN, Richardson-Klavehn A, Becker C, Thoma V, Heinze HJ, Düzel E (2005) Redefining implicit and explicit memory: the functional neuroanatomy of priming, remembering, and control of retrieval. Proc Natl Acad Sci U S A 102:1257-1262.

Schott BH, Richardson-Klavehn A, Henson RN, Becker C, Heinze HJ, Düzel E (2006) Neuroanatomical dissociation of encoding processes related to priming and explicit memory. J Neurosci 26:792-800.

Shrager Y, Kirwan CB, Squire LR (2008) Activity in both hippocampus and perirhinal cortex predicts the memory strength of subsequently remembered information. Neuron 59:547-553.

Shulman GL, Corbetta M, Buckner RL, Raichle ME, Fiez JA, Miezin FM, 
Petersen SE (1997) Top-down modulation of early sensory cortex. Cereb Cortex 7:193-206.

Spaniol J, Davidson PS, Kim AS, Han H, Moscovitch M, Grady CL (2009) Event-related $\mathrm{fMRI}$ studies of episodic encoding and retrieval: meta-analyses using activation likelihood estimation. Neuropsychologia 47:1765-1779.

Staresina BP, Davachi L (2006) Differential encoding mechanisms for subsequent associative recognition and free recall. J Neurosci 26:9162-9172.

Summerfield C, Greene M, Wager T, Egner T, Hirsch J, Mangels J (2006) Neocortical connectivity during episodic memory formation. PLoS Biol 4:e128.

Umarova RM, Saur D, Schnell S, Kaller CP, Vry MS, Glauche V, Rijntjes M, Hennig J, Kiselev V, Weiller C (2010) Structural connectivity for visuospatial attention: significance of ventral pathways. Cereb Cortex 20:121-129.

Uncapher MR, Wagner AD (2009) Posterior parietal cortex and episodic encoding: insights from fMRI subsequent memory effects and dualattention theory. Neurobiol Learn Mem 91:139-154.
Voss JL, Paller KA (2008) Brain substrates of implicit and explicit memory: the importance of concurrently acquired neural signals of both memory types. Neuropsychologia 46:3021-3029.

Voss JL, Baym CL, Paller KA (2008) Accurate forced-choice recognition without awareness of memory retrieval. Learn Mem 15:454-459.

Voss JL, Hauner KK, Paller KA (2009) Establishing a relationship between activity reduction in human perirhinal cortex and priming. Hippocampus 19:773-778.

Whittlesea BW, Williams LD (2000) The source of feelings of familiarity: the discrepancy-attribution hypothesis. J Exp Psychol Learn Mem Cogn 26:547-565.

Yonelinas AP (1999) The contribution of recollection and familiarity to recognition and source-memory judgments: a formal dual-process model and an analysis of receiver operating characteristics. J Exp Psychol Learn Mem Cogn 25:1415-1434. 